\title{
Radiological Correlation Between the Anterior Ethmoidal Artery and The Supraorbital Ethmoid Cell in Relation to Skull Base
}

\author{
Bajarang Prasad Sah ${ }^{1 *}$, Shyam Thapa Chettri ${ }^{1}$, Mukesh Kumar Gupta ${ }^{2}$, Shankar Prasad Shah ${ }^{1}$, \\ Deepak Poudel ${ }^{1}$ and Sriti Manandhar ${ }^{1}$ \\ ${ }^{1}$ Department of Otolaryngology and Head \& Neck Surgery, B.P. Koirala institute of Health Sciences, Dharan, Nepal \\ ${ }^{2}$ Department of Radiodiagnosis and Imaging, B.P. Koirala institute of Health Sciences, Dharan, Nepal
}

\begin{abstract}
Background: The anterior ethmoidal artery (AEA) is an important landmark in functional endoscopic sinus surgery. Iatrogenic injury may result in retraction of the artery into the orbit, with intra-orbital bleeding and possible blindness. Computerized Tomography (CT) scans are the gold standard in diagnosing paranasal sinus diseases. These scans are used as road maps while operating on the paranasal sinuses. We undertook this study to determine the reliability of identification of the artery on the coronal CT scan and to determine whether a correlation exists between the pneumatization of the suprabullar recess and the vertical distance of the artery from the base skull.

Methods: 80 randomly selected CT scans were studied. The AEA was identified on each side and the vertical distance between the artery and the base skull was measured. The CT scans were divided into two groups based on whether the supraorbital cell was present or absent. These groups were each further subdivided into 3 groups depending on the vertical distance between the anterior ethmoidal artery and the base skull.

Result: The AEA was reliably identified in $98.75 \%$ of the cases. When the supraorbital cell was absent, the mean distance between the artery and the base skull was $1.2 \mathrm{~mm}$; while when the cell was present, the mean distance was $4.52 \mathrm{~mm}$ which is statistical highly significant (p value $<0.05)$.

Conclusion: The orbital beak and superior oblique muscle are reliable landmarks to identify the anterior ethmoidal artery. There exists a strong correlation between the vertical distance of the artery from the base skull and the presence of the supraorbital ethmoid cell.
\end{abstract}

Keywords: Anterior Ethmoidal Artery, Supraorbital Ethmoidal Cell, Skull Base

\section{Introduction}

The lack of knowledge on endonasal surgical techniques, most specially its anatomy, was the main factor related to the high rate of complications seen associated to this surgical procedure during the 80 's'. Thus, identifying sinonasal anatomic structures and knowing its boundaries are essential for both the efficacy and the safety of nasosinusal endoscopic surgeries, regardless of the technique used ${ }^{[2]}$. The anterior ethmoidal artery (AEA) is an important landmark in functional endoscopic sinus surgery (FESS) and in endoscopic orbital decompression ${ }^{[3]}$. Iatrogenic injury to this artery during surgery may cause serious complications, such as intense bleeding, CSF leak, artery retraction towards the intra-orbital region and orbital hematoma formation. The development of a retro- orbital hemorrhage increases the pressure in this compartment; unless this is decompressed within approximately an hour it can lead to blindness ${ }^{[4,5]}$.

The anterior ethmoidal artery crosses three cavities: the orbit, the ethmoid labyrinth and the anterior fossa of the skull. In enters the olfactory fossa through the lateral lamella of the cribriform plate along the anterior ethmoidal sulcus, which is the point of greatest frailty of the whole anterior skull base. At this point the bone is extremely thin, and is considered as a high-risk area in nasal endoscopic surgery. In its course through the ethmoid labyrinth, the position of the anterior ethmoidal artery relative to the ethmoidal roof is very variable; the artery thus becomes vulnerable to injury during surgical procedures. ${ }^{[6.7]}$

Computerized Tomography (CT) scans are accepted as the gold standard in diagnosing diseases involving the paranasal sinuses. These scans are used as road maps while operating on the paranasal sinuses. Hence, it is essential for the otolaryngologist to be able to read the CT scan by himself. ${ }^{8]}$ Accurate localization of the AEA pre-operatively would help in avoiding damage to the artery. We undertook this study to determine the reliability of identification of the artery on the coronal CT scan and to determine whether a correlation exists between the pneumatization of the suprabullar recess and the vertical distance of the artery from the base skull.

\section{Materials and Methods}

This prospective descriptive cross-sectional study was conducted in Department of Otorhinolaryngology and 
head and neck surgery and department of Radiodiagnosis and imaging, B.P. Koirala Institute of Health Sciences Dharan,Nepal during a period from August 2014 to July 2015. A total of eighty patients (160 AEA) diagnosed clinically as chronic rhinosinusitis, who underwent CT scan of nose and paranasal sinus, were taken up for this study. The patients aged below 12 years, history of surgery or trauma in the paranasal sinuses or the skull base, Congenital anomalies of the face, paranasal sinus malignancies and Osteofibrous lesions were excluded from the study.Detail medical history was taken, thorough clinical examinations were performed and proforma were filled up. Ethical approval was obtained from the Institutional ethical review board (IERB) of B.P. Koirala Institute of health sciences. Written informed consent taken from participants prior to the study.

CT scans were performed using 16-slice multi-detector CT scanner (SIEMENS). The slice thickness of the scans was $3 \mathrm{~mm}$. These planes were made with patients in ventral decubitus, using perpendicular sections to the hard palate, from the anterior border of the frontal sinus to the anterior border of the clivus. The AEA was identified on coronal CT scans (bone windows) on each side and its distance from the base skull measured individually. The bony canal of the AEA was identified running across the ethmoidal cavity. The CT scans were divided into 2 groups, those with supraorbital cells and those in which supra-orbital cell (SO cell) is absent. Each group was further subdivided into 3 subgroups based on the distance of the AEA from the base skull as follows: Group I $-<2.5 \mathrm{~mm}$, Group II $-2.5-5$ $\mathrm{mm}$ and Group III $->5 \mathrm{~mm}$.

Data from filled proforma were entered in Microsoft Excel 2007 (Microsoft, Redmond, WA, USA) and were analyzed by using SPSS (Software Package for Social Sciences)16 for windows software. A descriptive analysis was made of the frequency distribution of qualitative variables. The chisquare test or student $t$ Test as applied as appropriate for comparing the prevalence of categorical variables. $\mathrm{P}$ values below or equal to 0.05 was defined as statistically significant.

\section{Result}

The eighty patients' CT scan of nose and PNS were studied and the following observations were made. The age ranges from 15years to 65years, the chronic rhinosinusitis was most common in the age group of 30 to 40 years. Out of total 80 patients, $30(37.5 \%)$ patients were from this group. The $46(58 \%)$ of the patients were female and $34(42 \%)$ were of the males. Ratio between female and male was 1.3:1. The commonest mode of presentation was nasal obstruction $77.5 \%$ followed by nasal discharge $42.5 \%$, headache $31.25 \%$, anosmia $26.25 \%$, nasal mass $22.5 \%$ and halotosis $18.75 \%$.

A total of 160 anterior ethmoidal artery were taken for the study and among them $156(97.5 \%)$ AEA could be identified and 4 (2.5\%) could not be identified. [Table- 1]

Most of the AEA were found at lower to the skull base level i.e. $105(67.3 \%)$ and at skull base level $51(32.7 \%)$. [Table-2]

When the SO cell was absent[fig.1], the anterior ethmoidal artery was seen close to the base skull $(<2.5 \mathrm{~mm})$ in $88.63 \%$ (78 out of 88 ) of the sides, while in the remaining $11.37 \%$ of the sides, it was seen at a distance of more than $2.5 \mathrm{~mm}$ (Groups II \& III) from the base skull. However, when the SO cell was present [fig.2], the anterior ethmoidal artery was seen at a distance of more than $2.5 \mathrm{~mm}$ (Groups II \& III) from the base skull in $88 \%$ (60 out of 68 ) of the sides, whereas it was close to the base skull in 11 only $12 \%$ of the sides (Group I) [Table-3]. When these two groups were analyzed for statistical significance (using the Chi-square test), the p value was 0.0001 , which is statistically highly significant.

When the SO cell was present, the mean distance of anterior ethmoidal artery from the skull base was $4.91 \mathrm{~mm}$ whereas when the SO cell was absent, the mean distance of anterior ethmoidal artery from the skull base was $1.3 \mathrm{~mm}$.[Table-4] When the mean distance of the AEA from the base skull for each group was compared (using the t-test), we found that the $\mathrm{p}$ value was 0.0001 , which is statistically highly significant.

Table 1: AEA identification on CT Scan

\begin{tabular}{|c|c|c|}
\hline AEA identification & No. of AEA & 97.5 \\
\hline Identified & 156 & 2.5 \\
\hline Unidentified & 4 & 100 \\
\hline Total & 160 & $1 \%)$ \\
\hline
\end{tabular}

Table 2; Location of AEA in relation to skull base

\begin{tabular}{|c|c|c|}
\hline Location of AEA & No. of AEA & Percentage (\%) \\
\hline At skull base & 51 & 32.7 \\
\hline Lower to skull base & 105 & 67.3 \\
\hline Total & $\mathbf{1 5 6}$ & $\mathbf{1 0 0}$ \\
\hline
\end{tabular}


Table 3: Distance between Anterior Ethmoidal Artery and Skull Base

\begin{tabular}{|c|c|c|}
\hline $\mathbf{n = 1 5 6}$ & Supraorbital cell present $(\mathbf{n}=\mathbf{6 8})$ & Supraorbital cell absents $(\mathbf{n}=\mathbf{8 8})$ \\
\hline Group I $(<2.5 \mathrm{~mm})$ & 8 & 78 \\
\hline Group II $(2.5-5 \mathrm{~mm})$ & 38 & 8 \\
\hline Group III $(>5 \mathrm{~mm})$ & 22 & 2 \\
\hline
\end{tabular}

Table 4: Mean distance of Anterior Ethmoidal Artery from Base Skull

\begin{tabular}{|c|c|c|c|} 
Supraorbital cell & $\mathbf{n}$ & $\begin{array}{c}\text { Mean distance of Anterior } \\
\text { Ethmoidal Artery from } \\
\text { Base Skull }\end{array}$ & P value \\
\hline Present & 68 & $4.91 \mathrm{~mm}$ & $<0.0001$ \\
\hline Absent & 88 & $1.3 \mathrm{~mm}$ & \\
\hline
\end{tabular}

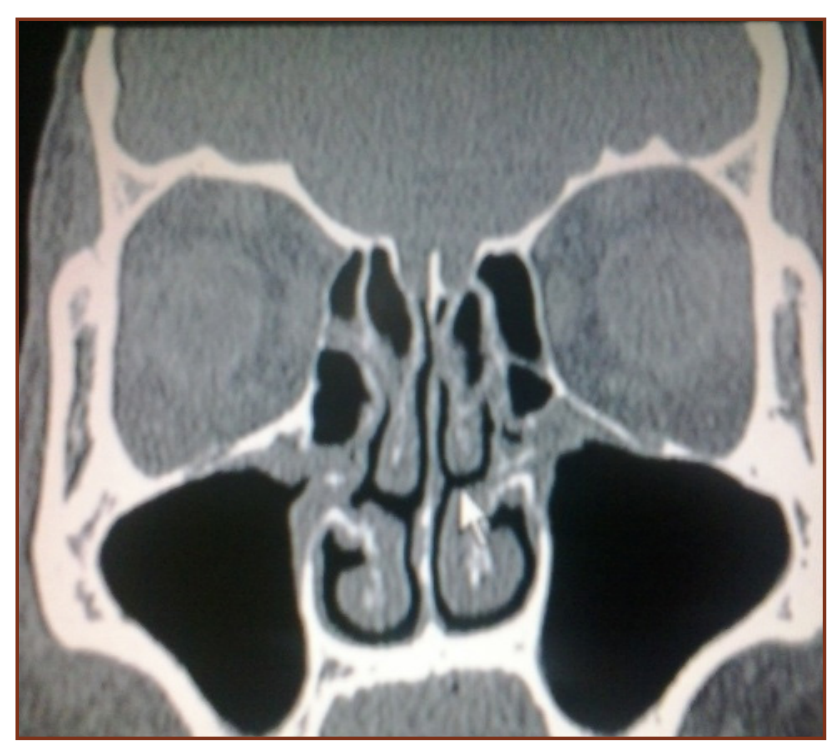

Fig. 1: Coronal CT scan without supraorbital cell showing AEA at skull Base.

\section{Discussion}

Correctly identifying the position of anterior ethmoidal artery prior to surgery helps minimize the complications that can occur in endoscopic sinus surgery such as perioperative bleeding, retro-orbital hemorrhage and a CSF leak. As Ohnishi et al. points out the area of the anterior ethmoid artery is prone to surgical complications. ${ }^{9}$

A thorough review of the literature revealed a few studies done with regards to the position of the AEA in the ethmoid cavity ${ }^{[2-4,6,7]}$. All the studies state that the vertical distance of the AEA from the base skull simple and reliable method of identifying the AEA on the CT scan. In addition, we present our data on the variability of the vertical distance of the AEA from the base skull. We have also found a correlation between the position of the AEA and the presence or absence of the supraorbital ethmoid cell.

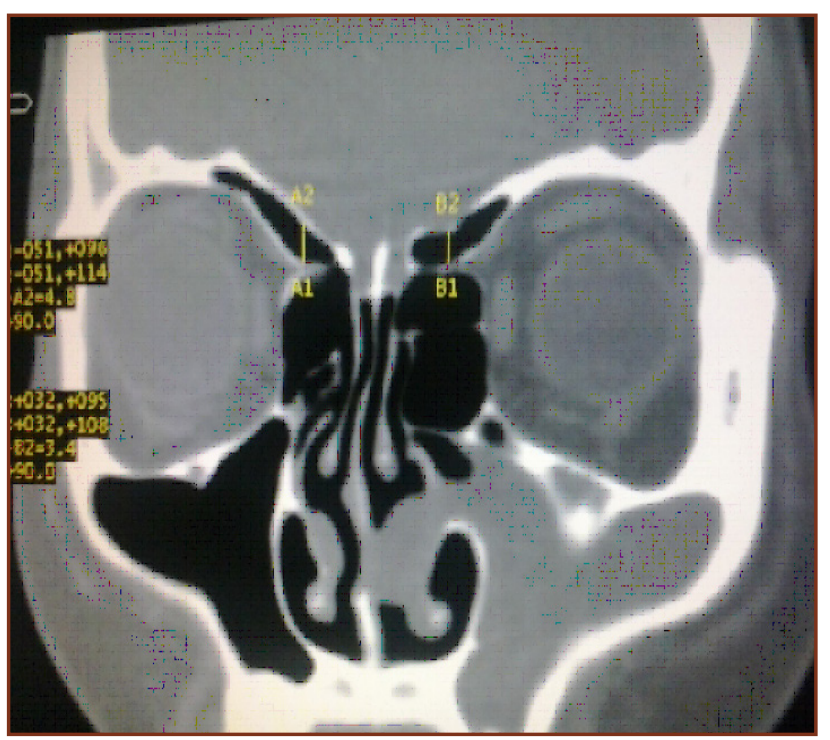

Fig. 2: Coronal CT scan with supraorbital cell showing measurement of vertical distance between anterior ethmoidal artery and base skull

We were able to identify the anterior ethmoidal artery in $97.5 \%$ of our patients. This figure is comparable to international literature. Joshi AA et al studied 50 patients and able to identify the anterior ethmoidal artery in $97 \%$ of patients ${ }^{[8]}$, similarly Mc Donald SE et al did study and found that the anterior ethmoidal foramen was visualized in 95 per cent of cases bilaterally ${ }^{[3]}$.

We used coronal CT scan in the bone windows to identify the AEA. The AEA was identified at the level of the orbital beak formed at the junction of the superior and the medial orbital wall. Another prominent landmark at this site was the presence of the superior oblique muscle in the orbit.

Also, the orbital beak is a constant bony landmark when compared to the vertical attachment of the middle turbinate which can be variable in position. However, the most important advantage of this method is that these landmarks 
are preserved even in extensive pathologies of the paranasal sinuses $^{[8]}$.

In our present study only $32.7 \%$ of the anterior ethmoidal arteries lay in the base skull, while the remaining $67.3 \%$ of the anterior ethmoidal arteries had a mesentery by which they were suspended below from the base skull. The study done by Joshi AA et al showed that only $20 \%$ of the arteries lay in the base skull, while the remaining $80 \%$ of the arteries had a mesentery by which they were suspended below from the base skull ${ }^{[8]}$. These figures indicate that the AEA is at risk during surgery in majority of the cases if it is not assessed carefully on the CT scan.

The presence of a supraorbital cell influences the relationship between the anterior ethmoidal artery and the skull base. The pneumatization of the ethmoid sinuses and the existence of a supraorbital cell, which is found in a variable percentage. In the present study we found that 68 out of $156(43.5 \%)$ patients had supraorbital cells pneumatisation and remaining $88(56.5 \%)$ patients had no supraorbital cells pneumatisation which is quite similar to the study done by Simmen D et al who found that $47 \%$ specimens had supraorbital cells pneumatisation and remaining $53 \%$ specimens had no supraorbital cells ${ }^{10}$, Joshi et al found that found that $44.4 \%$ patients had supraorbital cells pneumatisation and remaining $55.6 \%$ patients had no supraorbital cells ${ }^{8}$ and Chung et al ${ }^{11}$ and Souza et al ${ }^{12}$ had found supraorbital cells pneumatisation in $26 \%$ and $35 \%$ respectively, are factors that would influence the level of the AEA.

There exists a strong correlation between the vertical distance of the AEA from the base skull and the presence of the supraorbital ethmoid cell. In our study, it is shown that when the SO cell was absent, the anterior ethmoidal artery was seen close to the base skull $(<2.5 \mathrm{~mm})$ in $88.63 \%$ (78 out of 88 ) of the sides, while in the remaining $11.37 \%$ of the sides, it was seen at a distance of more than $2.5 \mathrm{~mm}$ (Groups II \& III) from the base skull. However, when the SO cell was present, the anterior ethmoidal artery was seen at a distance of more than $2.5 \mathrm{~mm}$ (Groups II \& III) from the base skull in $88 \%$ (60 out of 68 ) of the sides, whereas it was close to the base skull in 11 only $12 \%$ of the sides (Group I). When these two groups were analyzed for statistical significance (using the Chi-square test), the $\mathrm{p}$ value was 0.0001 , which is statistically highly significant. These findings are comparable with the study done by Joshi AA et al. They found that When the SO cell was absent, the anterior ethmoidal artery was seen close to the base skull $(<2.5 \mathrm{~mm})$ in $75.9 \%$ (41 out of 54$)$ of the sides, while in the remaining $24.1 \%$ of the sides, it was seen at a distance of more than $2.5 \mathrm{~mm}$ (Groups II \& III) from the base skull. When the SO cell was present, the anterior ethmoidal artery was seen at a distance of more than 2.5 $\mathrm{mm}$ (Groups II \& III) from the base skull in 86\% (37 out of 43) of the sides, whereas it was close to the base skull in only $14 \%$ of the sides (Group I) ${ }^{8}$

This study showed that when the SO cell was present, the mean distance of anterior ethmoidal artery from the skull base was $4.91 \mathrm{~mm}$ whereas when the SO cell was absent, the mean distance of anterior ethmoidal artery from the skull base was $1.3 \mathrm{~mm}$. When the mean distance of the AEA from the base skull for each group was compared (using the t-test), we found that the p value was 0.0001 , which is statistically highly significant. It means in cases where the supraorbital ethmoid cell is present, the AEA crosses the ethmoid cavity at a much lower level as compared to when the supraorbital ethmoid cell is absent.

Hence it must be kept in mind that the anterior ethmoidal artery is more susceptible to injury in cases when the supraorbital ethmoid cell is present. The position of the anterior ethmoidal artery may show variations between the two sides in a single patient. The possibility of such a variation must be known to the endoscopic sinus surgeon. Identification of the anterior ethmoidal artery preoperatively on the CT scan will help to minimize chances of damage to the artery during surgery.

\section{Conclusion}

The orbital beak and superior oblique muscle are reliable landmarks to identify the anterior ethmoidal artery. There exists a strong correlation between the vertical distance of the artery from the base skull and the presence of the supraorbital ethmoid cell.

\section{Acknowledgements}

We would like to thank the Faculties, residents and staffs of the Department of Otolaryngology and Head and Neck Surgery and Department of Radiodiagnosis and Imaging for their support and co-operation during this study and preparing the manuscript.

\section{Funding}

This study was funded by B.P. Koirala Institute of Health Sciences, Dharan, Sunsari, Nepal.

\section{Reference:}

1. Stankiewz JA. Complications of endoscopic intranasal ethmoidectomy. Laryngoscope 1987; 97:1270-3.

2. Moon Hyoung-Jin, Hyung-Ung Kim, Jeung-Gweon Lee, In Hyuk Chung. Surgical anatomy of the anterior ethmoidal canal in ethmoid roof. Laryngoscope 2001; 111:900-4.

3. McDonald S E, Robinson P J, Nunez D A. Radiological anatomy of the anterior ethmoidal artery for functional 
endoscopic sinus surgery. The Journal of Laryngol \& Otol 2008; 122:264-67.

4. Ohnishi T, Yanagisawa E. Endoscopic anatomy of the anterior ethmoidal artery. Ear Nose and Throat Journal 1994:634-6.

5. Voegels RL. Cirurgia endoscópica dos seios paranasais. Arquivos de otorrinolaringologia 1997;1(1).

6. Araujo Filho BC, Weber R, Pinheiro Neto CD, Lessa MM, Voegels RL, Butugan O. Endoscopic anatomy of the anterior ethmoidal artery: a cadaveric dissection study. Rev Bras Otorrinolaringol. (Engl Ed). 2006 ;72(3):303-8.

7. Pandolfo I, Vinci S, Salamone I, Granata F, Mazziotti S. Evaluation of the anterior ethmoidal artery by $3 \mathrm{D}$ dual volume rotational digital subtraction angiography and native multidetector CT with multiplanar reformations. Initial findings. Eur Radiol. 2007;17(6):1584-90.
8. Joshi AA, Shah KD, Bradoo RA. Radiological correlation between the anterior ethmoidal artery and the supraorbital ethmoid cell. Indian J Otolaryngol Head Neck Surg (JulySeptember 2010) 62(3) (Rhinology):299-303.

9. Ohnishi T., Tachibana T., Kaeko Y. et al. (1993) Highrisk areas in endoscopic sinus surgery and prevention of complications. Laryngoscope 103, 1181-1185

10. Simmen D, Raghavan U, Briner HR, Manestar M, Schuknecht B, Groscurth P et al. The surgeon's view of the anterior ethmoid artery. Clin Otolaryngol. 2006 Jun;31(3):187-91.

11. Chung SK, Dhong HJ, Kim HY. Computed tomography anatomy of the anterior ethmoid canal. Am J Rhinol 2001; 15:77-81.

12. Souza SA, Souza MM, Gregório LC, Ajzen S. Anterior ethmoidal artery evaluation on coronal CT scans. Braz J Otorhinolaryngol. 2009 Jan-Feb;75(1):101-6.

*Corresponding author:

Dr. Bajarang Prasad Sah, Associate professor, Department of Otolaryngology and Head \& Neck Surgery, B.P. Koirala institute of

Health Sciences, Dharan, Nepal

Phone: +919779842030356

Email: bpshah231@hotmail.com

Financial or other Competing Interests: None. 